\title{
Efficacy of adipose tissue-derived stem cells in locomotion recovery after spinal cord injury: a systematic review and meta-analysis on animal studies
}

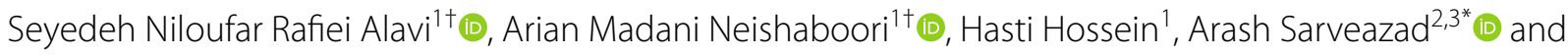
Mahmoud Yousefifard ${ }^{1 *}$ (1)

\begin{abstract}
Background: Considerable disparities exist on the use of adipose tissue-derived stem cells (ADSCs) for treatment of spinal cord injury (SCI). Hence, the current systematic review aimed to investigate the efficacy of ADSCs in locomotion recovery following $\mathrm{SCl}$ in animal models.

Methods: A search was conducted in electronic databases of MEDLINE, Embase, Scopus, and Web of Science until the end of July 2019. Reference and citation tracking and searching Google and Google Scholar search engines were performed to achieve more studies. Animal studies conducted on rats having SCI which were treated with ADSCs were included in the study. Exclusion criteria were lacking a non-treated control group, not evaluating locomotion, non-rat studies, not reporting the number of transplanted cells, not reporting isolation and preparation methods of stem cells, review articles, combination therapy, use of genetically modified ADSCs, use of induced pluripotent ADSCs, and human trials. Risk of bias was assessed using Hasannejad et al's proposed method for quality control of SCl-animal studies. Data were analyzed in STATA 14.0 software, and based on a random effect model, pooled standardized mean difference with a 95\% confidence interval was presented.

Results: Of 588 non-duplicated papers, data from 18 articles were included. Overall risk of bias was high risk in 8 studies, some concern in 9 studies and low risk in 1 study. Current evidence demonstrated that ADSCs transplantation could improve locomotion following SCI (standardized mean difference $=1.71 ; 95 \% \mathrm{Cl} 1.29-2.13 ; p<0.0001$ ). A considerable heterogeneity was observed between the studies $\left(I^{2}=72.0 \% ; p<0.0001\right)$. Subgroup analysis and metaregression revealed that most of the factors like injury model, the severity of $\mathrm{SCl}$, treatment phase, injury location, and number of transplanted cells did not have a significant effect on the efficacy of ADSCs in improving locomotion following $\mathrm{SCl}$ ( $p_{\text {for odds ratios }}>0.05$ ).
\end{abstract}

\footnotetext{
*Correspondence: arashsarveazad@gmail.com; yousefifard.m@iums.ac.ir † Seyedeh Niloufar Rafiei Alavi and Arian Madani Neishaboori contributed equally to this work.

1 Physiology Research Center, Iran University of Medical Sciences, Hemmat Highway, P.O Box: 14665-354, Tehran, Iran

${ }^{2}$ Colorectal Research Center, Iran University of Medical Sciences, Niayesh

St, Satarkhan Av, P.O Box: 14665-354, 1449614535 Tehran, Iran

Full list of author information is available at the end of the article
} permits use, sharing, adaptation, distribution and reproduction in any medium or format, as long as you give appropriate credit to the original author(s) and the source, provide a link to the Creative Commons licence, and indicate if changes were made. The images or other third party material in this article are included in the article's Creative Commons licence, unless indicated otherwise in a credit line to the material. If material is not included in the article's Creative Commons licence and your intended use is not permitted by statutory regulation or exceeds the permitted use, you will need to obtain permission directly from the copyright holder. To view a copy of this licence, visit http://creativecommons.org/licenses/by/4.0/. The Creative Commons Public Domain Dedication waiver (http://creativeco mmons.org/publicdomain/zero/1.0/) applies to the data made available in this article, unless otherwise stated in a credit line to the data. 
Conclusion: We conclude that any number of ADSCs by any prescription routes can improve locomotion recovery in an $\mathrm{SCl}$ animal model, at any phase of $\mathrm{SCl}$, with any severity. Given the remarkable bias about blinding, clinical translation of the present results is tough, because in addition to the complexity of the nervous system and the involvement of far more complex motor circuits in the human, blinding compliance and motor outcome assessment tests in animal studies and clinical trials are significantly different.

Keywords: Stem cell, Spinal cord injuries, Animal study, Meta-analysis

\section{Background}

Following spinal cord injury (SCI), a cascade of reactions occurs in the injured area, all of which can damage the nerve tissue. This nerve damage disrupts the neural connection between higher and lower parts of the injury; thus, it seems that the disabilities symptoms will persist until the affected area is healed and the active synapses between the upper and lower part of the injured spinal cord are restored $[1,2]$.

Today, cell transplantation is thought to be a viable treatment option in SCI. Research has suggested that cell transplantation to the damaged spinal cord is capable of producing new neural connections at the level of injury and improved locomotion [3-5]. There are different populations of stem cells, but they all fall into two pluripotent and multipotent groups. These cells have a continuous self-renewal capacity and can differentiate into somatic cells [6].

Much attention has now been paid to the use of adult stem cells, most commonly mesenchymal cells. There are various sources for these types of cells in the body, but adipose-derived mesenchymal stem cells (ADSCs) are one of the best sources available because they are easy to access and have excellent proliferation and differentiation properties. ADSCs are multipotent and can differentiate into mesenchymal and non-mesenchymal classes [7-9]. The cell population derived from adipose tissue is of mesenchymal origin and has low impurities of endothelial cells, smooth muscle cells, and pericytes. ADSCs enter the aging phase later than other cells, even after passing several passages, and can differentiate into adipogenic, osteogenic, chondrogenic, myogenic, and neurogenic cells [9-11]. These capabilities make them a proper candidate for SCI.

The characteristics and differentiation ability of ADSCs in vivo and in vitro have been widely described in the literature, but yet, there is no consensus on the neuronal healing ability and recovery of neurological symptoms after their transplantation following SCI. Therefore, the present systematic review and metaanalysis aimed to evaluate the effect of transplantation of ADSCs on the improvement of locomotion in preclinical models of SCI.

\section{Method}

Study design

This study is a systematic review and meta-analysis, conducted based on the Preferred Reporting Items for Systematic Reviews and Meta-Analyses (PRISMA) [12]. This study was not registered.

\section{PICO definition and eligibility criteria}

The description of PICO (Problem, Intervention, Comparison, Outcome) in the current study is as follows: the problem $(\mathrm{P})$ included the rats with SCI. The intervention (I) was the transplantation of ADSCs. The comparison $(\mathrm{C})$ compares the outcome in the treatment group with the result of the SCI group without treatment, and the interested outcome of the study $(\mathrm{O})$ was the improvement of animal locomotion.

Rat studies on SCI which were treated with ADSCs were included. Exclusion criteria included not having control group, not evaluating motor function recovery based on behavioral assessment test, using animal species other than rat, not reporting the number of transplanted cells, insufficient explanation about isolation and preparation of stem cells, review articles, use of combination therapy, use of genetically modified ADSCs, use of induced pluripotent ADSCs, and human trials.

\section{Search strategy}

The keywords related to "adipose-derived stem cell" and "spinal cord injury" were used to perform a comprehensive search on MEDLINE, Embase, Scopus, and Web of Science until the end of July 2019. Search queries in the databases are depicted in the Additional file 1. Also, a manual search was done in the bibliography of related articles and the Google Scholar search engine. Reference tracking and citation tracking of eligible studies were other strategy to achieve more relevant articles.

\section{Study selection and data collection}

After eliminating duplicate records, two independent researchers performed the initial screening studying titles and abstracts. Next, full texts of the potentially 
relevant articles were assessed and were selected based on the inclusion and exclusion criteria. Any disagreement was then resolved by discussion with a third researcher.

The extracted data included study design information, animals' age/weight and gender, SCI induction model, number of transplanted ADSCs, time interval between SCI and treatment, severity of injury, location of injury, transplantation type, number of studied animals, and the motor function score. SCI induction models included contusion (dropping a source of weight on the exposed spinal cord of animal model) [13], compression (clipping the exposed spinal cord of animal model) [14], hemisection (cutting the dorsal and ventral columns of the exposed spinal cord of animal model) [15], and crush (hitting the spine using a blower) [16] injury models. If the required data were not recorded in an article, the corresponding author was contacted. Majority of the studies reported the outcome of the intervention in several stages, so the last evaluation time was published in the current metaanalysis. In cases when the results were reported in graphs, Sistrom and Mergo data extraction method was used [17].

\section{Risk of bias assessment}

Quality assessment was evaluated using instructions proposed by Hasannejad et al. [18]. This tool includes 15 items regarding study design, animal characteristics, methodological quality of study, and analysis. The items are animals' species, using appropriate tests, severity of SCI induction, spinal level of SCI, age/weight of animals, number of animals per group, designation of strain, definition of control, description of statistical analysis, regulation and ethics, bladder expression of animals after SCI, blindness of assessor, genetic background of the included animals, method of allocation to treatments, and attrition.

Two independent reviewers assessed the included studies and determined the risk of bias of each item. Disagreements were resolved by discussion with a third researcher. No recommendations exist for the overall risk of bias score in Hassanejad et al's study. Therefore, we defined overall risk of bias consulting with an expert. Accordingly, the presence of at least one fetal error in the methodological approach was defined as high risk and presence of bias in other items without any fetal errors was considered as some concern of bias. Low risk of bias was scored when all items were low risk. Lack of blinding of assessor, not using standard test for assessment of locomotion, and not reporting the severity and level of $\mathrm{SCI}$ were considered as fetal errors.

\section{Data synthesis}

Studies were summarized based on locomotion recovery, and data were recorded as mean \pm standard deviation (SD). Since most of the animal studies reported standard error of mean (SEM) instead of SD, we calculated SD from SEM $(\mathrm{SD}=\mathrm{SEM} \times$ the square root of sample size in each group). For each separate experiment, the number of animals in each group, mean, and SD were recorded.

\section{Statistical analysis}

Statistical analyses were performed using STATA 14.0 statistical software. Our previous meta-analyses showed that the efficacy of stem cells therapy may vary among different methodological designs, such as diversities in animal species, number of transplanted stem cells, and type of graft $[4,19,20]$. Since the design of the included studies is heterogeneous, from a methodological point of view, a random effect model was used to analyze data. Heterogeneity between the studies was evaluated using the statistic $I^{2}$ and chi-squared test. In cases of heterogeneity, subgroup analysis was performed to determine the source of heterogeneity. Finally, the study results were pooled, and the overall effect size was presented. This effect size is calculated as standardized mean difference (SMD) with $95 \%$ confidence interval (95\% CI). Moreover, a sensitivity analysis was performed using leave-one-out approach to assess any individual study's effect on the pooled effect size. In addition, we performed a sensitivity analysis according to the overall risk of bias score. Publication bias was identified using Egger's tests [21].

\section{Results \\ Characteristics}

The search came up with 588 non-duplicate results. After initial screening and studying full texts of the articles, 18 articles were included in the current metaanalysis [13-16, 22-35] (Fig. 1). One of the articles presented two different sets of data [14], so the results from 19 unique experiments were analyzed. Two studies were in Chinese $[33,34]$, and 16 articles were in English [13-16, 22-32, 35]. Experiments were performed on 567 rats (275 rats in the SCI group and 292 rats in ADSCs-treated groups). Eight studies used the contusion model, and five studies used a compression model to create SCI. Injury severity was moderate in 11 articles and severe in seven studies. The time interval between SCI and treatment administration was between 0 and 14 days. SCI location was the thoracic region in 11 studies. Thirteen studies used intrathe$\mathrm{cal} /$ intraspinal ADSC administration, and five studies 


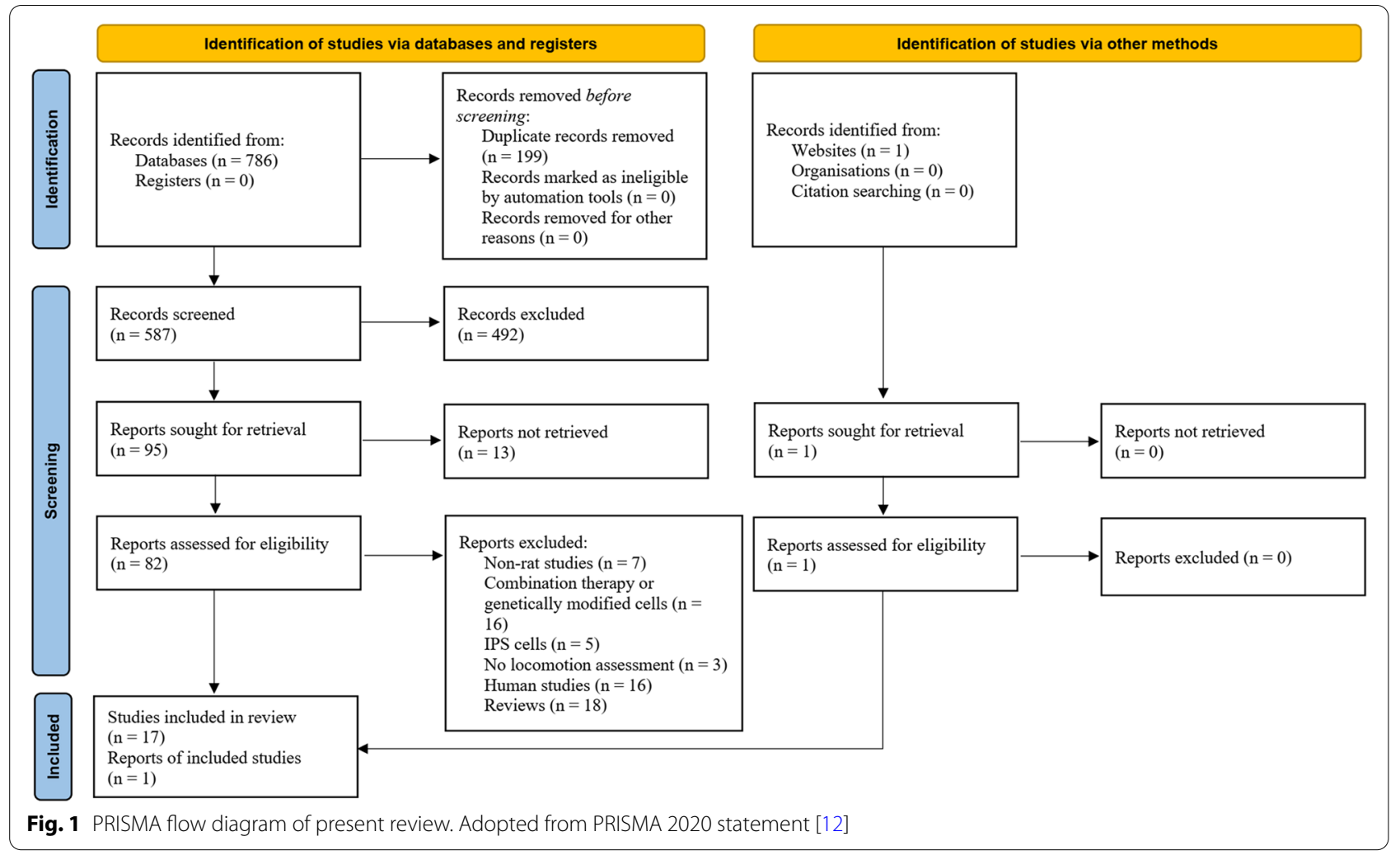

used intravenous administration. The number of transplanted cells varied between $1 \times 10^{5}$ and $2.5 \times 10^{6}$ cells. Table 1 summarizes the characteristics of the included studies.

\section{Risk of bias assessment and publication bias}

Quality control of the studies demonstrated that the risk of bias in attrition bias and blinding of the assessor sections was high in 14 articles and eight articles, respectively. Bladder expression was not reported in 6 articles (high risk). In other parts, the majority of the studies had a low risk of bias (Table 2). Overall risk of bias was high risk in 8 studies, some concern in 9 studies and low risk in 1 study. Finally, analyses showed that there was no publication bias in the current meta-analysis $(p=0.884)$ (Fig. 2).

\section{The effect of ADSCs on locomotion after SCI}

Random effect analysis demonstrated that ADSC transplantation can improve locomotion in rats following $\mathrm{SCI}(\mathrm{SMD}=1.71 ; 95 \%$ CI 1.29 to $2.13 ; p<0.0001)$. We performed an additional analysis based on fixed effect model. According to the fixed effect model, the analysis showed that the pooled SMD of ADSCs on locomotion recovery after SCI is 1.52 (95\% CI 1.32 to 1.71$)$. Therefore, both models show a significant beneficial effect of ADSCs administration on locomotion after SCI (Fig. 3).

Importantly, considerable heterogeneity was observed between the studies $\left(I^{2}=72.0 \% ; \mathrm{p}<0.0001\right)$. Hence, a subgroup analysis was performed (Fig. 3).

Subgroup analysis depicted that the severity of the injury and the number of transplanted cells were the two main sources of heterogeneity between the studies (Table 3). Univariate meta-regression showed that differences in injury model, the severity of SCI, treatment phase, injury location, number of transplanted cells, route of administration, type of graft, and follow-up duration did not have a significant effect on the efficacy of ADSCs improving locomotion following SCI ( $p_{\text {for odds }}$ ratios $>0.05)$. In other words, ADSCs seem to improve motor function in every setting (Table 3).

\section{Sensitivity analysis}

We used leave-one-out sensitivity analysis to explore any individual studies' effect on the pooled SMD. The analysis showed that excluding any of the included articles does not statistically affect the pooled SMD (Fig. 4). In addition, another sensitivity analysis based on the risk of bias score depicted that the pooled SMD of ADSCs transplantation after $\mathrm{SCI}$ in high risk of bias studies $(\mathrm{SMD}=1.28$; 95\% CI 0.66-1.90) did not significantly differ from studies 


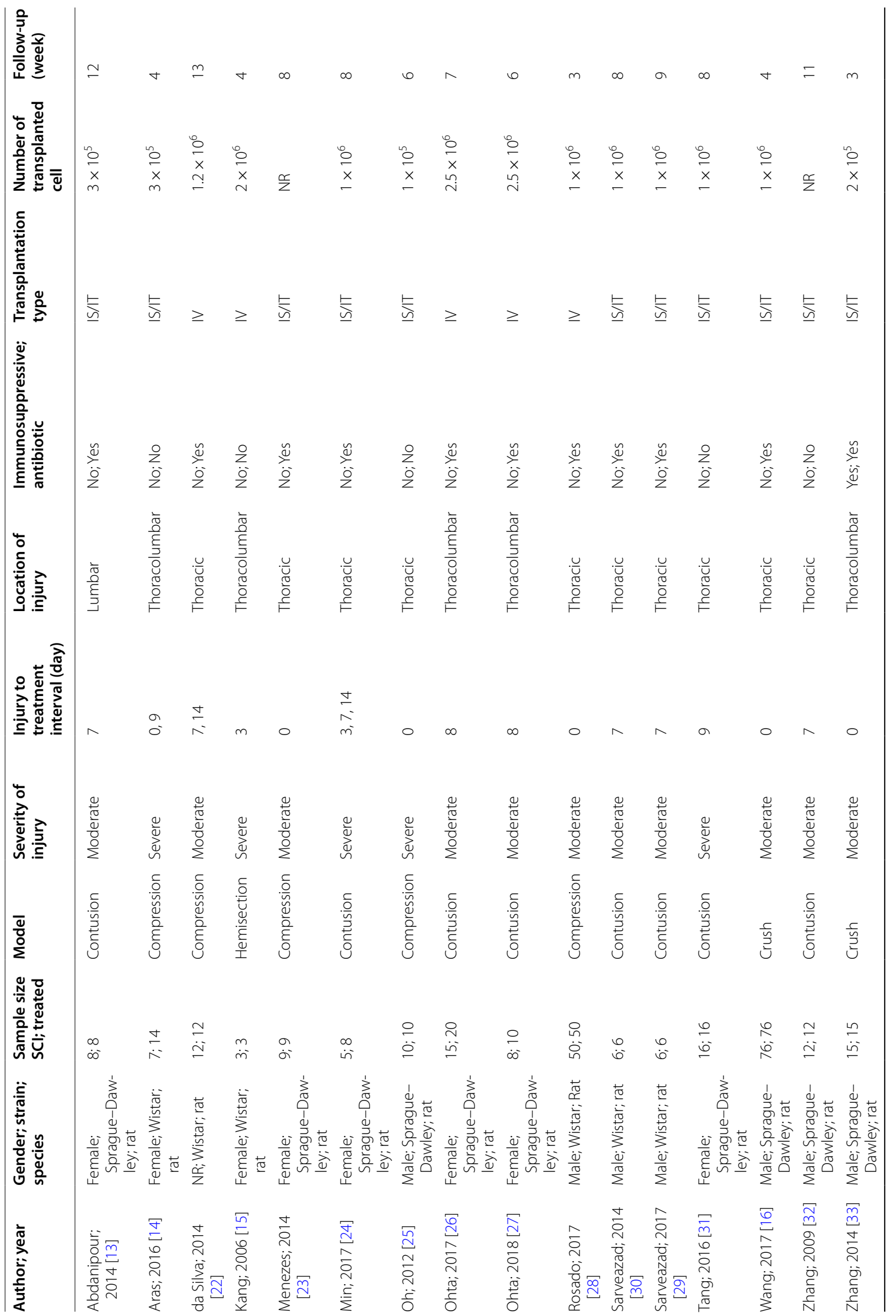




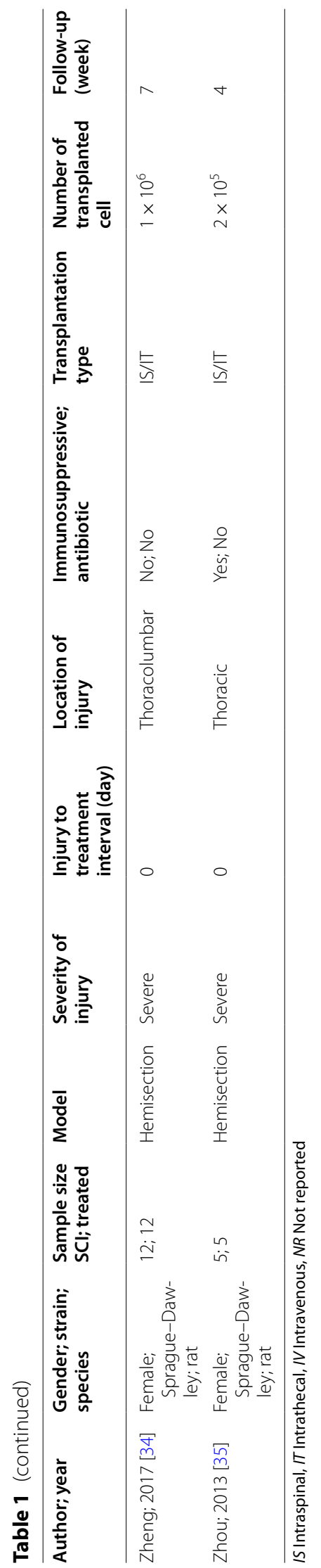


Table 2 Risk of bias assessment of included studies

\begin{tabular}{|c|c|c|c|c|c|c|c|c|c|c|c|c|c|c|c|c|}
\hline Study & Item 1 & Item 2 & Item 3 & Item 4 & Item 5 & Item 6 & Item 7 & Item 8 & Item 9 & Item 10 & Item 11 & Item 12 & Item 13 & Item 14 & Item 15 & Overall \\
\hline Abdanipour; 2014 & (:) & (;) & (:) & (:) & (i) & (:) & (;) & (;) & (:) & (;) & (:) & (;) & (:) & (;) & (2) & Some concern \\
\hline Aras; 2016 & (;) & (-) & (:) & (:) & (;) & (-) & (:) & (;) & (:) & (:) & (-) & (;) & (:) & (:) & (2) & Some concern \\
\hline da Silva; 2014 & (i) & (-) & (:) & (;) & (:) & (:) & (;) & (:) & (:) & (;) & (:) & (2) & (:) & (i) & (:) & High \\
\hline Kang; 2006 & (:) & (:) & (:) & (:) & (;) & (:) & (;) & (;) & (;) & (2) & (2) & (2) & (:) & (:) & (2) & High \\
\hline Menezes; 2014 & (;) & (;) & (:) & (:) & (;) & (:) & (;) & (:) & (;) & (:) & (;) & (;) & (:) & (:) & (2) & Some concern \\
\hline Min; 2017 & (;) & (:) & (:) & (;) & (;) & (;) & (:) & (:) & (;) & (;) & (;) & (:) & (:) & (:) & (:) & Low \\
\hline Oh; 2012 & (i) & (:) & (:) & (i) & (:) & (:) & (;) & (;) & (;) & (;) & (8) & (2) & (;) & (:) & (2) & High \\
\hline Ohta; 2017 & (i) & (:) & (:) & (:) & (;) & (;) & (:) & (:) & (;) & (;) & (;) & (2) & (:) & (i) & : (2) & High \\
\hline Ohta; 2018 & (;) & (;) & (:) & (;) & (;) & (:) & (:) & (:) & (;) & (;) & (:) & (2) & (;) & (:) & (2) & High \\
\hline Rosado; 2017 & (;) & (:) & (:) & (:) & (:) & (:) & (;) & (:) & (;) & (;) & (2) & (;) & (:) & (:) & (2) & Some concern \\
\hline Sarveazad; 2014 & (;) & (;) & (:) & (;) & (;) & (:) & (;) & (:) & (;) & (:) & (i) & (:) & (:) & (:) & (2) & Some concern \\
\hline Sarveazad; 2017 & (:) & (;) & (:) & (:) & (:) & (:) & (:) & (:) & (:) & (:) & (:) & (:) & (:) & (:) & (2) & Some concern \\
\hline Tang; 2016 & (;) & (-) & (:) & (:) & (;) & (:) & (;) & (-) & (;) & (:) & (2) & (;) & (:) & (:) & (;) & Some concern \\
\hline Wang; 2017 & (i) & (-) & (:) & (:) & (:) & (-) & (;) & (;) & (2) & (i) & (-) & (2) & (:) & (:) & (2) & High \\
\hline Zhang; 2009 & (:) & (:) & (:) & (:) & (:) & (:) & (:) & (:) & (:) & (:) & (2) & (2) & (:) & (:) & (:) & High \\
\hline Zhang; 2014 & (:) & (i) & (;) & (i) & (2) & (:) & (:) & (:) & (:) & (2) & (i) & (i) & (i) & (i) & (:) & Some concern \\
\hline Zheng; 2017 & (i) & (:) & (:) & (:) & (;) & (i) & (:) & (:) & (;) & (i) & (;) & (2) & (:) & (i) & (2) & High \\
\hline Zhou; 2013 & (:) & (:) & (:) & (:) & (:) & (:) & (:) & (;) & (:) & (;) & (2) & (;) & (:) & (:) & (2) & Some concern \\
\hline
\end{tabular}

(2), high risk of bias; ; , low risk of bias

Item 1, species; Item 2, using appropriate tests; Item 3, severity of injury; Item 4, level of injury; Item 5, age/weight; Item 6, number of animals per group; Item 7, designation of strain; Item 8, definition of control; Item 9, description of statistical analysis; Item 10, regulation and ethics; Item 11, bladder expression; Item 12, blindness of assessor; Item 13, genetic background; Item 14, method of allocation to treatments; Item 15, attrition

having some concern risk of bias $(\mathrm{SMD}=2.02 ; 95 \% \mathrm{CI}$ $1.43-2.61$; odds ratio $=2.10 ; 95 \%$ CI $0.71-6.21 ; p=0.168$; Table 3).

\section{Discussion}

The present study aimed to summarize the evidence regards the efficacy of ADSC transplantation on locomotor recovery following SCI in rats. Overall, the current meta-analysis showed that the ADSCs could significantly improve locomotor function following SCI in rats. This improvement is not affected by injury model, the severity of SCI, treatment phase, injury location, number of transplanted cells, route of administration, type of graft, and follow-up duration.

Regarding the injury model, although present metaanalysis did not show a significant relationship between the injury model and ADSCs efficacy, it should be noted that the number of studies included for the crush (2 studies) and hemisection (3 studies) models is low. Therefore, a definite conclusion on the relationship of motor function improvement after transplantation of ADSCs and injury model needs further experimental investigations.
ADSCs have anti-apoptotic, anti-inflammatory, antifibrotic, immunomodulatory, and angiogenesis properties due to the secretion of various cytokines [37]. These features of ADSCs, along with accessibility and abundance, make ADSCs, a suitable candidate for neural tissue repair [38]. ADSCs induce axonal regeneration, synaptogenesis, extracellular matrix (ECM) rearrangement, and angiogenesis through the expression of cytokines such as stem cell factor, neural growth factor, brain-derived neurotrophic factor, matrix metalloproteinase, and vascular endothelial growth factor and ultimately improve locomotion recovery [26, 39-42]. Antonic et al.s systematic review and meta-analysis on stem cell transplantation in traumatic SCI in animal studies also show that stem cells after SCI improve motor function [43]. They showed that in $70 \%$ of the studies, the Basso, Beattie, and Bresnahan $(\mathrm{BBB})$ locomotor scale used to assess motor status. They concluded that studies using other criteria besides the $\mathrm{BBB}$ reported less efficacy for stem cell therapy. This issue could be considered as a potential source of bias. Also, Antonic et al. showed that the blinding status of the observer was a significant issue when a behavioral test, such as the BBB, was performed. They reported 
Funnel plot with pseudo 95\% confidence limits

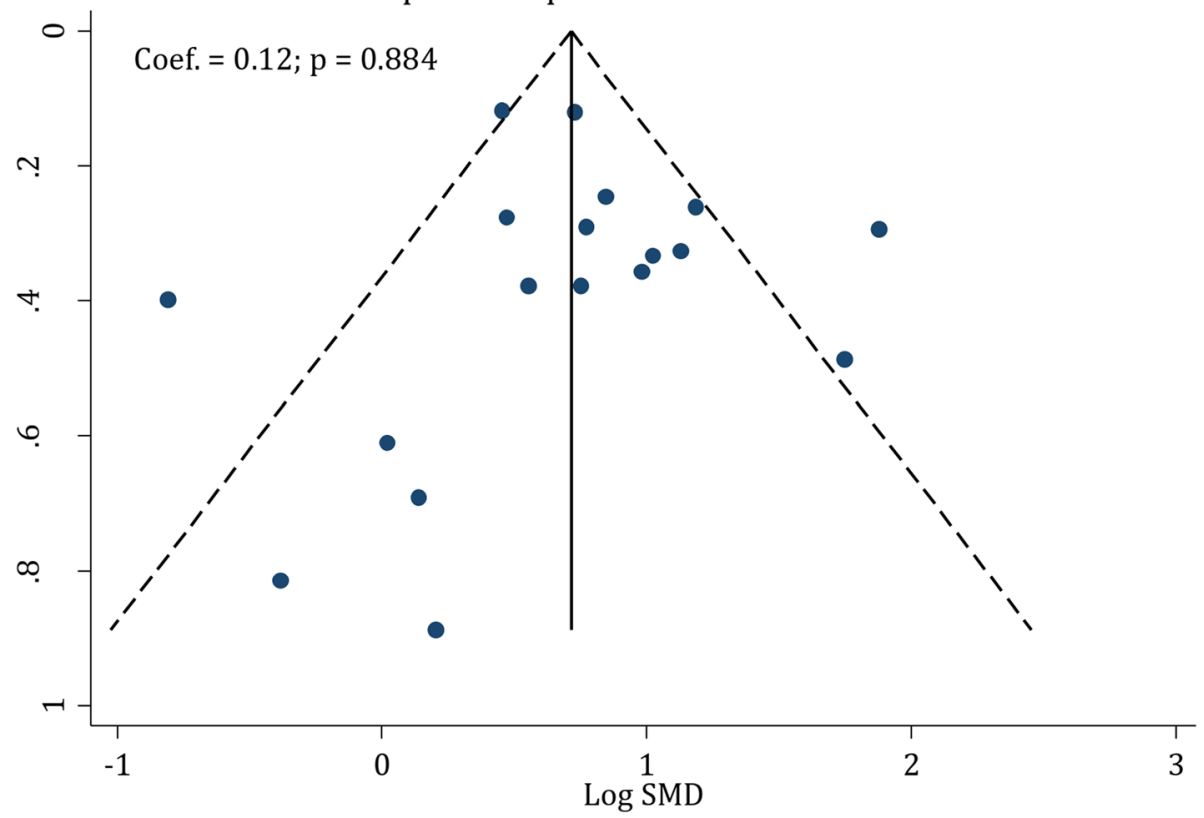

Fig. 2 Publication bias among included studies. There is no evidence of publication bias $(p=0.884)$

\begin{tabular}{|c|c|c|c|}
\hline Author & Year & $\operatorname{SMD}(95 \% \mathrm{CI})$ & $\begin{array}{l}\% \\
\text { Weight } \\
\text { (Fixed effect) }\end{array}$ \\
\hline Abdanipour & 2014 & $3.28(1.72,4.84)$ & 1.54 \\
\hline Aras & 2016 & $1.23(0.07,2.39)$ & 2.81 \\
\hline Aras & 2016 & $2.13(0.78,3.48)$ & 2.06 \\
\hline da Silva & 2014 & $0.00(-0.80,0.80)$ & 5.87 \\
\hline Kang & 2006 & $5.75(1.46,10.04)$ & 0.20 \\
\hline Menezes & 2014 & $1.74(0.64,2.84)$ & 3.09 \\
\hline Min & 2017 & $2.79(1.17,4.40)$ & 1.44 \\
\hline $\mathrm{Oh}$ & 2012 & $2.17(1.04,3.29)$ & 2.96 \\
\hline Ohta & 2017 & $0.45(-0.23,1.12)$ & 8.17 \\
\hline Ohta & 2018 & $1.15(0.14,2.16)$ & 3.67 \\
\hline Rosado & 2017 & $2.08(1.59,2.57)$ & 15.77 \\
\hline Sarveazad & 2016 & $3.09(1.33,4.86)$ & 1.20 \\
\hline Sarveazad & 2014 & $2.67(1.04,4.30)$ & 1.42 \\
\hline Wang & 2017 & $1.58(1.22,1.94)$ & 28.24 \\
\hline Tang & 2016 & $1.60(0.80,2.41)$ & 5.83 \\
\hline Zhang & 2009 & $1.02(0.17,1.88)$ & 5.14 \\
\hline Zhang & 2014 & $0.68(-0.06,1.42)$ & 6.91 \\
\hline Zheng & 2017 & $2.33(1.28,3.39)$ & 3.37 \\
\hline Zhou & 2013 & $6.54(3.11,9.98)$ & 0.32 \\
\hline \multirow{2}{*}{\multicolumn{2}{|c|}{$\begin{array}{l}\text { Fixed effect: Overall }(\mathrm{I}-\mathrm{squared}=72.0 \%, \mathrm{p}=0.000) \\
\text { Random effect Overall }\end{array}$}} & $1.52(1.32,1.71)$ & 100.00 \\
\hline & & $1.71(1.29,2.13)$ & \\
\hline & $T$ & & \\
\hline & -10 & & \\
\hline
\end{tabular}


Table 3 Subgroup analysis of adipose tissue derived stem cells on motor function recovery after spinal cord injury

\begin{tabular}{|c|c|c|c|c|c|c|}
\hline Subgroup & $\begin{array}{l}\text { Number of } \\
\text { experiments }\end{array}$ & Heterogeneity ( $p$ value) & SMD (95\% Cl) & $P$ value & OR $(95 \% \mathrm{Cl})$ & $P$ value \\
\hline \multicolumn{7}{|l|}{ Injury model } \\
\hline Contusion/compression & 14 & $71.1 \%(<0.0001)$ & $1.65(1.15-2.15)$ & $<0.0001$ & Ref & - \\
\hline Crush & 2 & $71.9 \%(<0.0001)$ & $1.19(0.32-2.06)$ & 0.008 & $0.61(0.14-2.64)$ & 0.481 \\
\hline Hemisection & 3 & $72.0 \%(<0.0001)$ & $4.45(1.33-7.57)$ & 0.005 & $6.26(0.94-41.65)$ & 0.306 \\
\hline \multicolumn{7}{|l|}{ Severity of SCI } \\
\hline Moderate & 11 & $77.3 \%(p<0.0001)$ & $1.42(0.91-1.94)$ & $<0.0001$ & Ref & - \\
\hline Sever & 8 & $48.8 \%(p=0.057)$ & $2.23(1.55-2.91)$ & $<0.0001$ & $2.30(0.76-6.93)$ & 0.129 \\
\hline \multicolumn{7}{|l|}{ Treatment phase } \\
\hline Immediate and acute & 10 & $64.7 \%(p=0.003)$ & $1.89(1.38-2.40)$ & $<0.0001$ & Ref & - \\
\hline Sub-acute & 9 & $73.8 \%(p<0.0001)$ & $1.50(0.82-2.18)$ & $<0.0001$ & $0.61(0.20-1.85)$ & 0.362 \\
\hline \multicolumn{7}{|l|}{ Injury location } \\
\hline Thoracic & 11 & $72.3 \%(<0.0001)$ & $1.81(1.28-2.33)$ & $<0.0001$ & Ref & - \\
\hline Thoracolumbar and lumbar & 8 & $70.9 \%(0.001)$ & $1.29(0.85-2.32)$ & $<0.0001$ & $0.76(0.24-2.42)$ & 0.620 \\
\hline \multicolumn{7}{|l|}{ Number of transplanted cell } \\
\hline$\leq 5.0 \times 10^{5}$ & 6 & $75.4 \%(0.001)$ & $2.14(1.07-3.20)$ & $<0.0001$ & Ref & - \\
\hline $5.1 \times 10^{5}$ to $1.0 \times 10^{6}$ & 6 & $28.1 \%(0.224)$ & $1.91(1.55-2.26)$ & $<0.0001$ & $1.10(0.25-4.72)$ & 0.890 \\
\hline$>1.0 \times 10^{6}$ & 5 & $75.0 \%(0.003)$ & $1.17(0.14-2.19)$ & 0.026 & $0.40(0.09-1.97)$ & 0.237 \\
\hline \multicolumn{7}{|l|}{ Route of administration } \\
\hline Intraspinal/intrathecal & 14 & $57.0 \%(0.004)$ & $1.89(1.46-2.32)$ & $<0.0001$ & Ref & - \\
\hline Intravenous & 5 & $86.7 \%(<0.0001)$ & $1.18(0.11-2.25)$ & 0.031 & $0.43(0.13-1.35)$ & 0.138 \\
\hline \multicolumn{7}{|l|}{ Type of graft } \\
\hline Allograft & 11 & $62.5 \%(0.003)$ & $1.64(1.22-2.05)$ & $<0.0001$ & Ref & - \\
\hline Xenograft & 7 & $80.7 \%(<0.0001)$ & $1.91(0.86-2.95)$ & $<0.0001$ & $1.40(0.44-4.41)$ & 0.542 \\
\hline Autograft & 1 & NA & NA & NA & NA & NA \\
\hline \multicolumn{7}{|l|}{ Follow-up duration } \\
\hline 3-4 weeks & 7 & $72.7 \%(0.001)$ & $1.78(1.12-2.44)$ & $<0.0001$ & Ref & - \\
\hline 5-7 weeks & 6 & $75.0 \%(0.007)$ & $1.46(0.51-2.41)$ & 0.003 & $0.65(0.13-3.19)$ & 0.573 \\
\hline 8-13 weeks & 7 & $74.4 \%(<0.0001)$ & $1.85(1.04-2.65)$ & $<0.0001$ & $0.93(0.23-3.69)$ & 0.911 \\
\hline \multicolumn{7}{|l|}{ Risk of bias } \\
\hline Low risk & 1 & NA & NA & NA & NA & NA \\
\hline Some concern & 10 & $64.6 \%(0.003)$ & $2.02(1.43-2.61)$ & $<0.001$ & Ref & - \\
\hline High risk & 8 & $75.9(<0.001)$ & $1.28(0.66-1.90)$ & $<0.001$ & $2.10(0.71-6.21)$ & 0.168 \\
\hline
\end{tabular}

Severity of injury was categorized based on the definition given in the article by Cheriyan et al. [36]

CI Confidence interval, NA Not applicable due to limited number of studies in the category, OR Odds ratio, Ref. Reference category, SCI Spinal cord injury, SMD Standardized mean difference

that studies examining locomotor outcomes would fail to reach a definitive conclusion about efficacy if they did not report blinding. Locomotion recovery findings and blinding bias in our study are consistent with the results of Antonic et al.

In the randomized clinical trials, blinding is far more important than animal studies. Systematic review and meta-analysis by $\mathrm{Xu}$ et al. in 2019 showed that mesenchymal stem cell transplantation in SCI patients did not affect improving motor function [44]. A systematic review and meta-analysis of Fan et al. in 2017 investigated the safety and efficacy of stem cell transplantation in SCI patients. All studies included in this meta-analysis (except one study) used mesenchymal stem cells. The results of this study showed that stem cell transplantation is safe in SCI patients but has no efficacy in improving motor function. In their meta-analysis, only two of 10 articles had no blinding [45]. Thus, at least part of the reason for the discrepancy in the effect of stem cells on improving motor function between metaanalysis of animal studies and clinical trials could be related to the application of various tests in the evaluation of motor improvement and blinding compliance in most clinical trials. However, the leading cause is 


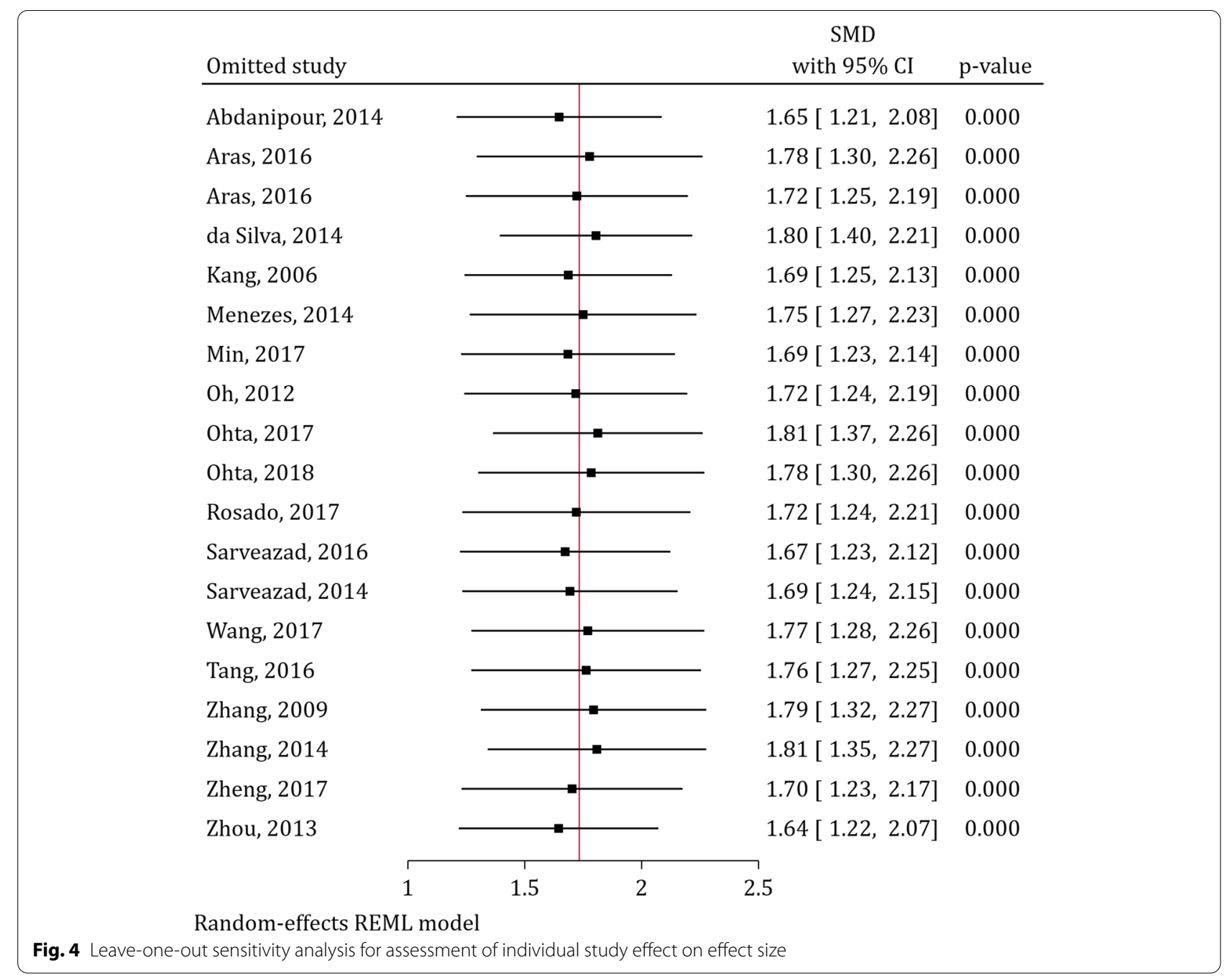

the complexity of the nervous system and the involvement of far more complex circuits in the human motor system.

Worth to mention that sometimes, choosing a wrong statistical model may lead to inaccurate results, and using fixed or random effect models under different meta-analytical scenarios may result in different findings. Although we decided to use random effect model to pool the results of included studies, using fixed effect or random effect model did not change the overall results. The pooled SMD of fixed effect model and random effect model for effect of ADSCs on locomotion after SCI are 1.52 (95\% CI 1.32 to 1.71) and 1.71 (95\% CI 1.29 to 2.13), respectively. Therefore, even though we used a random effect model based on our expectation of heterogeneity among included studies, both models showed a significant beneficial effect of ADSCs on locomotion after SCI.

\section{Conclusion}

We conclude that any number of ADSCs by any prescription routes can improve locomotion recovery if administered in an SCI animal model, at any phase of SCI, with any severity. But given the remarkable bias about blinding, it is tough to clinical translation of the present results, because in addition to the complexity of the nervous system and the involvement of far more complex motor circuits in the human, blinding compliance and motor outcome assessment tests in animal studies and clinical trials are significantly different.

\section{Abbreviations}

ADSC: Adipose tissue-derived stem cells; BBB: Basso, Beattie, and Bresnahan; CI: Confidence interval; ECM: Extracellular matrix; IS: Intraspinal; IT: Intrathecal; IV: Intravenous; NA: Not applicable; NR: Not reported; OR: Odds ratio; PICO: Problem, Intervention, Comparison, Outcome; PRISMA: Preferred Reporting Items for Systematic Reviews and Meta-Analyses; Ref:: Reference category; SCI: Spinal cord injury; SMD: Standardized mean difference. 


\section{Supplementary Information}

The online version contains supplementary material available at https://doi. org/10.1186/s13643-021-01771-W.

Additional file 1. Search query for databases.

\section{Acknowledgements}

None.

\section{Registration}

The review was not registered.

\section{Protocol accessibility}

Protocol was not prepared.

\section{Role of the sponsor}

The Iran University of Medical Sciences had no role in the design and conduct of the study and collection, management, and analysis of the data.

\section{Authors' contributions}

Conception or design of the work: MY and AS. Data acquisition: All authors. Analysis: MY. Drafting the work: SNRA, AMN, and MY. Revising draft critically for important intellectual content: All authors. The author(s) read and approved the final manuscript.

\section{Funding}

This research has been supported by Iran University of Medical Sciences (Grant number: 97-3-75-12823).

\section{Availability of data and materials}

All data generated or analyzed during this study are included in this published article.

\section{Declarations}

\section{Ethics approval and consent to participate}

The study was approved by Iran University of Medical Sciences Ethics Committee. The inform consent was not applicable for the present meta-analysis.

\section{Consent for publication}

Not applicable.

\section{Competing interests}

On behalf of all authors, the corresponding author states that there is no conflict of interest.

\section{Author details}

${ }^{1}$ Physiology Research Center, Iran University of Medical Sciences, Hemmat Highway, P.O Box: 14665-354, Tehran, Iran. ${ }^{2}$ Colorectal Research Center, Iran University of Medical Sciences, Niayesh St, Satarkhan Av, P.O Box: 14665-354, 1449614535 Tehran, Iran. ${ }^{3}$ Nursing Care Research Center, Iran University of Medical Sciences, Tehran, Iran.

Received: 5 October 2020 Accepted: 21 July 2021

Published online: 31 July 2021

\section{References}

1. Alizadeh A, Dyck SM, Karimi-Abdolrezaee S. Traumatic spinal cord injury: an overview of pathophysiology, models and acute injury mechanisms. Front Neurol. 2019;10:282

2. Shao A, Tu S, Lu J, Zhang J. Crosstalk between stem cell and spinal cord injury: pathophysiology and treatment strategies. Stem Cell Res Ther. 2019;10(1):238

3. Yousefifard M, Nasirinezhad F, Manaheji HS, Janzadeh A, Hosseini M Keshavarz M. Human bone marrow-derived and umbilical cord-derived mesenchymal stem cells for alleviating neuropathic pain in a spinal cord injury model. Stem Cell Res Ther. 2016;7(1):36.

4. Yousefifard M, Maleki SN, Askarian-Amiri S, Vaccaro AR, Chapman JR, Fehlings MG, et al. A combination of mesenchymal stem cells and scaffolds promotes motor functional recovery in spinal cord injury: a systematic review and meta-analysis. J Neurosurg Spine. 2019;1(aop):1-16.

5. Yousefifard M, Nasirinezhad F. Review of cell therapy in spinal cord injury; effect on neuropathic pain. J Med Physiol. 2017;2(2):34-44.

6. Bhartiya D. Pluripotent stem cells in adult tissues: struggling to be acknowledged over two decades. Stem Cell Rev Rep. 2017;13(6):713-24.

7. De Girolamo L, Arrigoni E, Stanco D, Lopa S, Di Giancamillo A, Addis A, et al. Role of autologous rabbit adipose-derived stem cells in the early phases of the repairing process of critical bone defects. J Orthop Res. 2011:29(1):100-8.

8. Ebrahimian T, Pouzoulet F, Squiban C, Buard V, André M, Cousin B, et al. Cell therapy based on adipose tissue-derived stromal cells promotes physiological and pathological wound healing. Arterioscler Thromb Vasc Biol. 2009:29(4):503-10.

9. Estes BT, Diekman BO, Gimble JM, Guilak F. Isolation of adipose-derived stem cells and their induction to a chondrogenic phenotype. Nat Protoc. 2010;5(7):1294-311.

10. Gimble JM, Guilak F, Bunnell BA. Clinical and preclinical translation of cellbased therapies using adipose tissue-derived cells. Stem Cell Res Ther. 2010;1(2):19.

11. Meyerrose T, Olson S, Pontow S, Kalomoiris S, Jung Y, Annett G, et al. Mesenchymal stem cells for the sustained in vivo delivery of bioactive factors. Adv Drug Deliv Rev. 2010;62(12):1167-74.

12. Page MJ, McKenzie JE, Bossuyt PM, Boutron I, Hoffmann TC, Mulrow CD, et al. The PRISMA 2020 statement: an updated guideline for reporting systematic reviews. Syst Rev. 2021;10(1):89.

13. Abdanipour A, Tiraihi T, Taheri T. Intraspinal transplantation of motoneuron-like cell combined with delivery of polymer-based glial cell line-derived neurotrophic factor for repair of spinal cord contusion injury. Neural Regen Res. 2014;9(10):1003-13.

14. Aras Y, Sabanci PA, Kabatas S, Duruksu G, Subasi C, Erguven M, et al. The effects of adipose tissue-derived mesenchymal stem cell transplantation during the acute and subacute phases following spinal cord injury. Turk Neurosurg. 2016;26(1):127-39.

15. Kang SK, Shin MJ, Jung JS, Kim YG, Kim CH. Autologous adipose tissuederived stromal cells for treatment of spinal cord injury. Stem Cells Dev. 2006;15(4):583-94.

16. Wang W, Peng H. PEP-1-SOD1 improves the therapeutic potential of transplanted adipose-derived mesenchymal stem cells in spinal cord injury. J Biomater Tissue Eng. 2017;7(12):1313-8.

17. Sistrom $C_{L}$, Mergo PJ. A simple method for obtaining original data from published graphs and plots. Am J Roentgenol. 2000;174(5):1241-4.

18. Hassannejad Z, Sharif-Alhoseini M, Shakouri-Motlagh A, Vahedi F, Zadegan SA, Mokhatab M, et al. Potential variables affecting the quality of animal studies regarding pathophysiology of traumatic spinal cord injuries. Spinal Cord. 2016;54(8):579-83.

19. Yousefifard M, Rahimi-Movaghar V Nasirinezhad F, Baikpour M, Safari S, Saadat $\mathrm{S}$, et al. Neural stem/progenitor cell transplantation for spinal cord injury treatment; A systematic review and meta-analysis. Neuroscience. 2016;322:377-97.

20. Hosseini M, Yousefifard M, Aziznejad H, Nasirinezhad F. The effect of bone marrow-derived mesenchymal stem cell transplantation on allodynia and hyperalgesia in neuropathic animals: a systematic review with metaanalysis. Biol Blood Marrow Transplant. 2015;21(9):1537-44.

21. Egger M, Smith GD, Schneider M, Minder C. Bias in meta-analysis detected by a simple, graphical test. BMJ. 1997;315(7109):629-34

22. da Silva AJ, Villanova JA, Fracaro L, Rebelatto CLK, Barchiki F, de Moura $S A B$, et al. Effect of mesenchymal stem cells on movement and urination of rats with spinal cord injury. Semin-Cienc Agrar. 2014;35(6):3205-14.

23. Menezes K, Nascimento MA, Goncalves JP, Cruz AS, Lopes DV, Curzio B, et al. Human mesenchymal cells from adipose tissue deposit laminin and promote regeneration of injured spinal cord in rats. PLoS One. 2014;9(5):e96020.

24. Min J, Kim JH, Choi $\mathrm{KH}$, Yoon HH, Jeon SR. Is there additive therapeutic effect when GCSF combined with adipose-derived stem cell in a rat model of acute spinal cord injury? J Korean Neurosurg Soc. 2017;60(4):404-16 
25. Oh JS, Park IS, Kim KN, Yoon DH, Kim SH, Ha Y. Transplantation of an adipose stem cell cluster in a spinal cord injury. Neuroreport. 2012;23(5):277-82.

26. Ohta $Y$, Hamaguchi A, Ootaki $M$, Watanabe $M$, Takeba $Y$, liri T, et al. Intravenous infusion of adipose-derived stem/stromal cells improves functional recovery of rats with spinal cord injury. Cytotherapy. 2017;19(7):839-48.

27. Ohta Y, Takenaga M, Hamaguchi A, Ootaki M, Takeba Y, Kobayashi T, et al Isolation of adipose-derived stem/stromal cells from cryopreserved fat tissue and transplantation into rats with spinal cord injury. Int J Mol Sci. 2018;19(7):1963.

28. Rosado IR, Carvalho PH, Alves EG, Tagushi TM, Carvalho JL, Silva JF, et al. Immunomodulatory and neuroprotective effect of cryopreserved allogeneic mesenchymal stem cells on spinal cord injury in rats. Genet Mol Res. 2017;16(1). https://doi.org/10.4238/gmr16019555.

29. Sarveazad A, Babahajian A, Bakhtiari M, Soleimani M, Behnam B, Yari A et al. The combined application of human adipose derived stem cells and Chondroitinase $\mathrm{ABC}$ in treatment of a spinal cord injury model. Neuropeptides. 2017;61:39-47.

30. Sarveazad A, Bakhtiari M, Babahajian A, Janzade A, Fallah A, Moradi F, et al. Comparison of human adipose-derived stem cells and chondroitinase $\mathrm{ABC}$ transplantation on locomotor recovery in the contusion model of spinal cord injury in rats. Iran J Basic Med Sci. 2014;17(9):685-93.

31. Tang L, Lu X, Zhu R, Qian T, Tao Y, Li K, et al. Adipose-derived stem cells expressing the neurogenin-2 promote functional recovery after spinal cord injury in rat. Cell Mol Neurobiol. 2016;36(5):657-67.

32. Zhang H-T, Luo J, Sui L-S, Ma X, Yan Z-J, Lin J-H, et al. Effects of differentiated versus undifferentiated adipose tissue-derived stromal cell grafts on functional recovery after spinal cord contusion. Cell Mol Neurobiol. 2009;29(8):1283

33. Zhang $X$, Chen $Y$. Effects of combination of human adipose- derived mesenchymal stem cells transplantation and treadmill training on locomotor functional recovery after incomplete spinal cord injury in rats. Chin J Rehabil Med. 2014;29(6):504-10.

34. Zheng HB, Luo L, Chen L. Tissue-engineered spinal cord construction by chitosan alginate scaffold and adipose-derived mesenchymal stem cells in the treatment of acute spinal cord injury. Chin J Tissue Eng Res. 2017;21(26):4199-204

35. Zhou Z, Chen Y, Zhang H, Min S, Yu B, He B, et al. Comparison of mesenchymal stromal cells from human bone marrow and adipose tissue for the treatment of spinal cord injury. Cytotherapy. 2013;15(4):434-48.
36. Cheriyan T, Ryan DJ, Weinreb JH, Cheriyan J, Paul JC, Lafage V, et al. Spinal cord injury models: a review. Spinal Cord. 2014;52(8):588-95.

37. Bertolini F, Lohsiriwat $\mathrm{V}$, Petit JY, Kolonin MG. Adipose tissue cells, lipotransfer and cancer: a challenge for scientists, oncologists and surgeons. Biochim Biophys Acta Rev Cancer. 2012;1826(1):209-14.

38. Kalbermatten DF, Schaakxs D, Kingham PJ, Wiberg M. Neurotrophic activity of human adipose stem cells isolated from deep and superficial layers of abdominal fat. Cell Tissue Res. 2011;344(2):251-60.

39. Carelli S, Colli M, Vinci V, Caviggioli F, Klinger M, Gorio A. Mechanical activation of adipose tissue and derived mesenchymal stem cells: novel anti-inflammatory properties. Int J Mol Sci. 2018;19(1):267.

40. Masgutov RF, Masgutova GA, Zhuravleva MN, Salafutdinov II, Mukhametshina RT, Mukhamedshina YO, et al. Human adipose-derived stem cells stimulate neuroregeneration. Clin Exp Med. 2016;16(3):451-61.

41. Rehman J, Traktuev D, Li J, Merfeld-Clauss S, Temm-Grove CJ, Bovenkerk $J \mathrm{E}$, et al. Secretion of angiogenic and antiapoptotic factors by human adipose stromal cells. Circulation. 2004;109(10):1292-8.

42. Sarveazad A, Janzadeh A, Taheripak G, Dameni S, Yousefifard M, Nasirinezhad F. Co-administration of human adipose-derived stem cells and low-level laser to alleviate neuropathic pain after experimental spinal cord injury. Stem Cell Res Ther. 2019;10(1):183.

43. Antonic A, Sena ES, Lees JS, Wills TE, Skeers P, Batchelor PE, et al. Stem cell transplantation in traumatic spinal cord injury: a systematic review and meta-analysis of animal studies. PLoS Biol. 2013;11(12):e1001738.

44. Mai CL, Wei X, Gui WS, Xu YN, Zhang J, Lin ZJ, et al. Differential regulation of GSK-3beta in spinal dorsal horn and in hippocampus mediated by interleukin-1 beta contributes to pain hypersensitivity and memory deficits following peripheral nerve injury. Mol Pain. 2019;15:1744806919826789.

45. Fan X, Wang JZ, Lin XM, Zhang L. Stem cell transplantation for spinal cord injury: a meta-analysis of treatment effectiveness and safety. Neural Regen Res. 2017;12(5):815.

\section{Publisher's Note}

Springer Nature remains neutral with regard to jurisdictional claims in published maps and institutional affiliations.
Ready to submit your research? Choose BMC and benefit from:

- fast, convenient online submission

- thorough peer review by experienced researchers in your field

- rapid publication on acceptance

- support for research data, including large and complex data types

- gold Open Access which fosters wider collaboration and increased citations

- maximum visibility for your research: over $100 \mathrm{M}$ website views per year

At BMC, research is always in progress.

Learn more biomedcentral.com/submissions 